\title{
Harnessing Plant Plasmid Curing Activity as an Alternative Approach to the Antibiotic Resistance Problem
}

\section{Opinion}

Volume 2 Issue 1- 2021

\author{
Author Details \\ Amanda Leckband ${ }^{1}$, Edward Dratz ${ }^{2}$, Noelle Bryan ${ }^{3}$, and David Sands ${ }^{1 *}$ \\ Department of Plant Sciences and Plant Pathology, Montana State Univiversity, USA \\ ${ }^{2}$ Department of Biochemistry, Montana State University, USA \\ ${ }^{3}$ Cenla Environmental Science, Alexandra, LA, USA \\ *Corresponding author \\ David Sands, Department of Plant Sciences and Plant Pathology, Montana State University, USA \\ Article History \\ Received: January 18, 2021 Accepted: January 19, 2021 Published: January 21, 2021
}

Keywords: Bacterial pathogens, Plasmid, Viral diseases, Aplinia galangal, Salmonella typhi, Staphylococcus

\section{Opinion}

Control of bacterial pathogens has become increasingly difficult, as many pathogens have acquired multiple antibiotic resistance and virulence traits, largely by plasmid mediated gene transfer systems [1]. Such plasmid mediated mechanisms can lead to transfer of multiple antibiotic resistance and virulence traits to related pathogens. Plasmid curing (reduction or elimination) activity has been demonstrated in four different plant species, presumably as a defense against bacterial and viral diseases.

Could the increasing problem of plasmid mediated antibiotic resistance in humans and animals be addressed by employing plant defense systems? This approach would be directed to curing the bacteria of the plasmids that carry traits for antibiotic resistance and hypervirulence, rather than to directly attack their bacterial carriers. Researchers have reported that root extracts of Aplinia galangal were capable of curing plasmids in a variety of multidrug resistant, clinically relevant bacteria [2]. Similar plasmid curing characteristics have also been discovered in two other plants, Discourdea and Plumbago [3]. Experiments with extracts of Chitrak from these plants showed that Salmonella typhi (strain R136) was cured of virulence plasmids [4]. Fermented olive leaves have been shown to have potential antibacterial activities in plasmid profiling and plasmid curing in Staphylococcus and Streptococcus mutants [5]. Xiao et al, [6]) reported plasmid curing activity in Chinese ginger.

Our interest has been focused on a search for plasmid curing systems existing in cultivars of crop plants, especially those being used in feed and food systems. We initially observed that a certain heirloom cultivar accession of Ethiopian barley demonstrated effective bacterial plasmid curing in leaf extracts [7]. Ethiopia was one of the two geographic regions where 8,000 years of domestication of barley took place [8]. We considered the possibility that as barley populations were domesticated and served as a main food source, they may have also served as a source of plasmid curing activities. During the gradual domestication of barley, populations may have been repeatedly selected for resistance to several common bacterial pathogens that harbored plasmids. In this way, some land race populations of barley could have contributed to maintaining the health of the subsistence farming communities. Selections from these land races of barley could now serve as a beneficial staple food for humans and as a feed for domesticated animals now and in the future.

We have determined that a leaf extract of a certain barley cultivar (MSU 121) elicit curing of E. coli plasmids carrying both ampicillin resistance traits and green fluorescent protein plasmid markers (Figure 1). The initial results showed a modest but positive effect. We have determined in feeding studies that a leaf extract of the same cultivar of barley has been extremely effective in curing calf and lamb scours (manuscript in preparation).

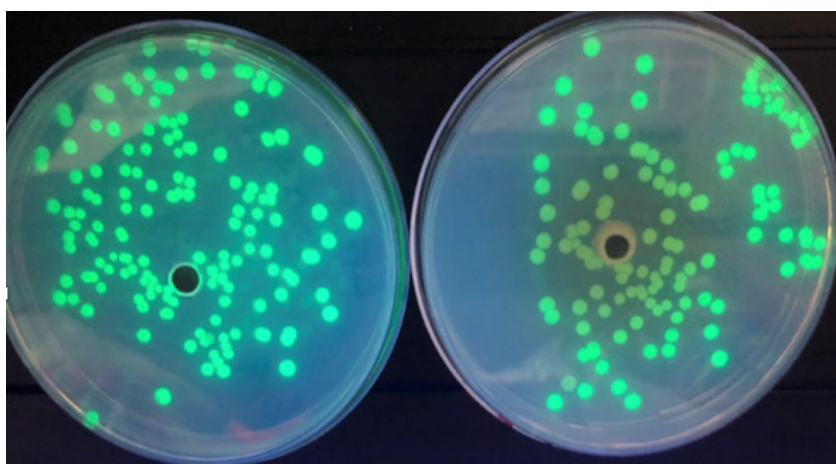

Figure 1: Green Fluorescent Protein carried on a plasmid in control and E. coli bacteria colonies treated with leaf extract of barley MSU-121. The colony count of MSU-121 treated cells is observed to be lower 24 hours after the barley extract has been placed onto the dish. 
We wish to alert other researchers that they can use similar assays to screen candidate plant-based feed components for plasmid curing activities. There are several different molecular mechanisms that elicit plasmid curing in microbes and these can be deployed in combination. Potentially, these are causally attributed to several viruses and several types of bacteria. This plant-based approach to "kill the messenger not the bacterium" may be a strategy to consider for those researchers that are confronting the dilemma of ever-increasing antibiotic resistance. This simple yet ingenious biological approach could potentially change the approach of attacking and eradicating antibiotic resistance.

\section{References}

1. Spengler G. Annamária Molnár, Zsuzsanna Schelz, Leonard Amaral, Derek Sharples, et al., (2006) The mechanism of plasmid curing in bacteria. Curr. Drug Targets 7(7): 823-841.

2. Latha C (2009) Antiplasmid activity of $1^{\prime}$-acetoxychavicol acetate from Alpinia galanga against multi-drug resistant bacteria. Journal of ethnopharmacology 123(3): 522-525.

3. Beg Arina Z, Iqbal Ahmad (2000) Effect of Plumbago zeylanica extract and certain curing agents on multidrug resistant bacteria of clinical origin. World Journal of Microbiology and Biotechnology 16(8-9): 841844.

4. Singh, Udai Pratap, Poonam Yadav, MP Goutam (2018) Antimicrobial Efficacy of Traditionally Used Plant Chitrak Plumbago zeylanica. Asian Man (The)-An International Journal 12(2): 161-172.

5. Buckner, Michelle MC, Maria Laura Ciusa, Laura JV Piddock. (2018) Strategies to combat antimicrobial resistance: anti-plasmid and plasmid curing. FEMS microbiology reviews 42(6): 781-804.

6. Lin Xiao, Hai-Fei Jia, In-Hong Jeong, Young-Joon Ahn, Yong-Zhe Zhu (2017) Isolation and Characterization of 2,4-D Butyl Ester Degrading Acinetobacter sp. ZX02 from a Chinese Ginger Cultivated Soil. J Agric Food Chem 65(34): 7345-7351.

7. Miller RV (1993) Chemotherapeutic Elimination of Genetic Components (doctoral dissertation). Montana State University, Bozeman, MT, USA, pp.196.

8. Harlan, Jack Rodney (1992) Crops and man. No. edn. 2. American Society of Agronomy. 